Federal Reserve Bank of Dallas

Globalization and Monetary Policy Institute

Working Paper No. 49

http://www.dallasfed.org/assets/documents/institute/wpapers/2010/0049.pdf

\title{
Asymmetries and State Dependence: The Impact of Macro Surprises on Intraday Exchange Rates
}

\author{
Rasmus Fatum \\ University of Alberta \\ Michael Hutchison \\ University of California, Santa Cruz \\ Thomas Wu \\ University of California, Santa Cruz
}

June 2010

\begin{abstract}
The impact of news surprises on exchange rates depends in principle upon a number of factors including the state of the economy, institutional setting and nature of the expected policy response. These characteristics may lead to state-contingent asymmetric responses to news. In this paper we investigate the possible asymmetric response of intraday exchange rates (5-minute intraday JPY/USD) to macroeconomic news announcements during a very unusual period-Japan during 1999-2006 when the money market interest rate was effectively zero. We may think of this period as a "natural experiment" consisting of an institutional setting when interest rates may rise but not decline, thereby constraining both endogenous policy reactions to news and private market expectations. Asymmetric responses to news, to the extent that they are important in exchange rate markets as they are in equity markets, would seem particularly likely to be evident during this period. We consider several ways asymmetric responses may be manifested and linked to macroeconomic news during the zero-interest rate period. We assess whether the intraday exchange rate responds differently depending on whether the news is emanating from Japan or the U.S; we consider the state of the business cycle; and we distinguish between "good" and "bad" news.

JEL codes: F31, G15, C22

* Rasmus Fatum, School of Business, University of Alberta, Edmonton, Alberta, Canada T6G 2R6. 780- 492-3951. rasmus.fatum@ualberta.ca. Michael Hutchison, Department of Economics, University of California, Santa Cruz, Santa Cruz, CA 95064. 831-459-2600. hutch@ucsc.edu. Thomas Wu, Department of Economics, University of California, Santa Cruz, Santa Cruz, CA 95064. 831-459-4453. thomaswu@ucsc.edu. Fatum and Hutchison are also members of the Economic Policy Research Unit (EPRU) at the University of Copenhagen and the Santa Cruz Institute for International Economics (SCIIE) at UC Santa Cruz. Fatum gratefully acknowledges financial support from Social Sciences and Humanities Research Council of Canada (SSHRC). We have benefitted greatly from detailed comments provided by Chris Neely. We thank Jesper Pedersen and Michael Simmons for help with the data. The views in this paper are those of the authors and do not necessarily reflect the views of the Federal Reserve Bank of Dallas or the Federal Reserve System.
\end{abstract}




\section{Introduction}

Recent research on the influence of U.S. macroeconomic news surprises on the dynamics of intraday exchange rates offers important insights regarding how quickly exchange rate markets react to macro news and which macro news are essential for explaining exchange rate movements (see, for example, Andersen et al., 2003 and 2007; Chaboud et al., 2004; Dominguez and Panthaki, 2006; and Faust et al., 2005). Generally, these intraday exchange rate studies suggest that stronger than expected U.S. economic activity and higher than expected inflation tends to appreciate the USD, and, furthermore, that U.S. news produces conditional mean jumps in the exchange rate.

The impact of news surprises on exchange rates depends in principle upon a number of factors including the state of the economy, institutional setting and nature of the expected policy response, e.g. Clarida and Waldman (2007) and Engel et al. (2007). ${ }^{1}$ These characteristics may lead to state-contingent asymmetric responses of exchange rates to news. Policy and private sector responses may be complicated and vary depending on factors such as the state of the business cycle, the nature of the macroeconomic news (e.g. "good" or "bad" news), and the (country) source of the news. Asymmetric responses are even more likely in particular institutional settings such as an environment with effectively zero short-term interest rates. Lower interest rates (below zero) are not feasible during this circumstance and hence monetary policy is not able to endogenously absorb shocks to certain news announcements, thereby limiting private sector expectations of policy reactions. Given the close linkages between interest rates

\footnotetext{
${ }^{1}$ These authors emphasize how expectations regarding central bank policy responses to inflation are formed in the context of exchange rate models.
} 
and exchanges rates, such constraints, in turn, are likely to make the response to news in the foreign exchange market state contingent.

Despite its theoretical importance, the empirical intraday literature on exchange rates has paid relatively little attention to whether the exchange rate response to macroeconomic news is asymmetric or state dependent across different dimensions. This is surprising since in investigations of macroeconomic news and assets prices, other than exchange rates, state dependence has been shown to be important (e.g. Andersen et al., 2007; Basistha and Kurov, 2008; Flannery and Protopapadakis, 2002; McQueen and Roley, 1993). In the context of equity markets and news, for example, McQueen and Roley (1993) have shown that the effect of news on stock prices is asymmetric in that it varies with the stages of the business cycle and that the equity price response may depend on whether a given news variable is conveying "good" or "bad" news about the state of the economy. ${ }^{2}$ These results for equity returns are confirmed and extended in Flannery and Protopapadakis (2002). Basistha and Kurov (2008) find that the response of U.S. equity returns to monetary news surprises is much stronger during recessions and tight credit conditions.

We investigate the possible asymmetric response of intraday exchange rates (5minute intraday JPY/USD) to macroeconomic news announcements during a very

\footnotetext{
${ }^{2}$ Using daily data, McQueen and Roley (1993) show that news regarding unexpectedly strong economic activity in the U.S. has a positive effect on the S\&P 500 index when business conditions are weak, but a negative effect when business conditions are strong. They attribute this asymmetry to differences in the response of discount rates relative to expected cash flows given different states of the economy. They argue that studies not accounting for differences in the business cycle may lead to an underestimation of the effects of announcement surprises. Andersen et al. (2007) consider the possible asymmetric effects of U.S. news surprises across different stages of the U.S. business cycle. They note that the effects of U.S. macroeconomic news on equities and bonds react differently depending on the state of the U.S. business cycle and, therefore, correlations averaged over the business cycle are typically low. They do not make this observation for exchange rates.
} 
unusual period - Japan during 1999-2006 when the money market interest rate was effectively zero (figure 1). Asymmetric responses to news, to the extent that they are important in exchange rate markets as they are in equity markets, would seem particularly likely to be evident during this period, i.e. we may think of this period as a "natural experiment" consisting of an institutional setting where interest rates may rise but not decline, thereby limiting the policy response to news announcements and, as a result, limiting private market expectations of endogenous policy actions. In such an institutional setting, the exchange rate is more likely to exhibit asymmetric responses to news compared to the environments that Andersen et al. (2007) consider, in which they do not find state contingent impacts of news on exchange rates. ${ }^{3}$

How might these state dependencies be distinguished? We consider three ways that state dependencies and asymmetric responses of intraday exchange rates may be manifested and linked to macroeconomic news: (1) whether the news emanates from Japan or the U.S.; (2) the state of the business cycle; and (3) differences between "good" and "bad" news. Accordingly, our first research question pertains to whether both U.S. and Japanese macro news surprises influence the JPY/USD exchange rate, i.e. whether Japanese news matter and, if so, which Japanese news are important and how do their relative influence compare to the relative influence of U.S. news. ${ }^{4}$ The second research question pertains to whether news has asymmetric exchange rate effects across different stages of the business cycle. Since our data set of macro news surprises for both the U.S. and Japan spans different combinations of U.S. and Japan business cycle upturns and

\footnotetext{
${ }^{3}$ Andersen et al. (2007) do not consider Japanese news announcements.

${ }^{4}$ Other studies that take into account Japanese macro news when analyzing the intraday JPY/USD exchange rate include Cai et al. (2001), Clarida and Waldman (2007), Ito and Roley (1987), and Melvin and Yin (2000). See Almeida et al. (1998), Andersen et al. (2003), and Bauwens et al. (2005) for studies that consider the intraday exchange rate response to both U.S. and European macroeconomic news.
} 
downturns, we are able to assess if business cycle asymmetries are present in our exchange rate context. Finally, our third research question is whether "good" and "bad" (positive and negative) news exert asymmetric intraday effects on the exchange rate, e.g. is the absolute magnitude of the exchange rate movement attributed to a positive (i.e. better than expected) Japanese GDP surprise different than the absolute magnitude of the movement associated with a negative (i.e. worse than expected) Japanese GDP surprise.

We shed light on these possible asymmetries by analyzing the real-time (intraday) effects of both U.S. and Japanese macroeconomic news surprises on the JPY/USD exchange rate over the 1 January 1999 to 31 October 2006 time-period. News data consisting of a large number of time-stamped U.S. and Japanese macroeconomic announcements and preceding survey expectations obtained from Bloomberg News Service, along with indicative 5-minute spot JPY/USD exchange rate quotes, facilitate our investigation. Both U.S. and Japanese news surprises are measured as the difference between the macroeconomic announcement and the median value of the immediately preceding Bloomberg News Service survey of market expectations regarding the given announcement. $^{5}$

For our baseline estimations, we estimate the exchange rate response to news surprises using only observations within 10-minutes before and 90-minutes after each announcement. To accommodate the long memory and the intraday periodicity that characterize our intraday JPY/USD exchange rate data, we estimate our baseline models using heteroskedasticity and serial-correlation robust (HAC) standard errors. To ensure the robustness of our results we also carry out estimations that include all the

\footnotetext{
${ }^{5}$ Fatum and Scholnick (2008) show that failure to disentangle the expected component of news may lead to an underestimation of the impact of news.
} 
observations in our sample and, furthermore, we re-estimate the baseline model using the two-step weighted least squares (2WLS) estimation. ${ }^{6}$

The following two sections discuss our data and our econometric methodology, respectively. Section 4 presents the baseline results, the methodological robustness checks, and assessment of asymmetries. Section 5 summarizes our results and concludes.

\section{Data}

The intraday JPY/USD exchange rate data is provided by Olsen and Associates, collected from commercial banks by Tenfore and Oanda, and covers the 1 January 1999 to 31 October 2006 time-period. The data consists of the bid and the offer spot exchange rate at the end of every 5-minute interval over every 24 -hour period. The quotes are indicative quotes, i.e. not necessarily traded quotes. We filter the data for anomalies and bad quotes following the procedure of Dacorogna et al. (1993).

Our midpoint $(\log )$ exchange rate price at each 5-minute point is constructed by linearly interpolating the average of the preceding and immediately following (log) bid and offer quotes. The continuously compounded 5-minute returns $\left(R_{t}\right)$ are calculated as the change in the 5-minute midpoint prices. $^{7}$ Consistent with the existing intraday literature on widely traded currency pairs we define a trading day to start at 21.05 GMT the night before and end at 21.00 GMT on the evening of the trading day in question (see Bollerslev and Domowitz, 1993) and, furthermore, we define a weekend to start at 21.05 GMT Friday and finish at 21.00 GMT Sunday.

\footnotetext{
${ }^{6}$ Our baseline estimation procedure follows Andersen et al. (2007). The 2WLS estimation procedure is described in Andersen and Bollerslev (1998).

${ }^{7}$ Goodhart et al. (1996) show that 5-minute returns constructed from indicative quotes closely resemble 5minute returns constructed from transaction prices.
} 
Our news data consists of a large number of time-stamped Japanese and U.S. macroeconomic announcements and preceding survey expectations obtained from Bloomberg News Service. ${ }^{8}$ We include in our analysis Japanese news variables that are largely comparable to the U.S. news variables that are significant in either the time-series analysis or the event study analysis of Andersen et al. (2003) in their investigation of the JPY/USD exchange rate. In addition, we consider surprises regarding Japanese news of particular interest, e.g. surprises regarding the Bank of Japan's TANKAN survey variables. ${ }^{9}$ We include U.S. news variables that Andersen et al. (2003) find to significantly influence the JPY/USD exchange rate, and we also take into account additional "usual suspects" variables such as surprises regarding U.S. consumer and producer price indices. Consequently, our data includes announcements and survey expectations regarding 16 types of Japanese macro news and 19 types of U.S. macro news. The Japanese news variables are GDP (quarterly), GDP (annual), Industrial Production, Capacity Utilization, Construction Orders, Overall Spending, Large Retail Sales, Trade Balance, Current Account, Retail Trade, Consumer Price Index, Consumer Confidence Index, TANKAN Large Manufacturing Index, TANKAN NonManufacturing Index, Leading Economic Index, and Monetary Base. The U.S. news variables are GDP, Non-Farm Payroll Employment, Industrial Production, Capacity Utilization, Personal Income, Consumer Credit, Consumer Spending, New Home Sales, Durable Good Orders, Factory Orders, Business Inventories, Trade Balance, Producer

\footnotetext{
${ }^{8}$ Japanese macro announcements are available from Bloomberg News Service as well as from the data banks of the Bank of Japan and the Japanese Cabinet Office.

9 The Bank of Japan website at www.boj.or.jp/en/theme/research/stat/tk/index.htm provides details (in English) regarding the TANKAN survey variables.
} 
Price Index, Consumer Price Index, Consumer Confidence Index, NAPM Index, Housing Starts, Index of Leading Indicators, and Target Federal Funds Rate.

Consistent with the recent literature on exchange rates and news, for each of the macroeconomic announcements in our data we define a news surprise as the difference between the macroeconomic announcement and the preceding survey expectation of that announcement. Subsequently, we standardize each news surprise series in order to allow for a comparison of the relative influences of different types of news. ${ }^{10}$

Table 1 displays details regarding the Japanese news surprises. ${ }^{11}$ The table shows the number of non-zero news surprises, the announcement frequency, and the start date of each of the Japanese news variable series. ${ }^{12}$

The timing of economic upturns and downturns for the U.S. follows the Business Cycle Dating Committee of the National Bureau of Economic Research. Business cycle dating for Japan is set in accordance with peaks and troughs of the Japanese industrial production index. Peaks (troughs) are identified as the highest (lowest) level of industrial production during an economic expansion (contraction). ${ }^{13}$ Table 2 shows the dates for

${ }^{10}$ A standardized news surprise is given by the unexpected component of the macroeconomic announcement divided by the associated sample standard deviation. Let $A_{q, t}$ denote the value of a given macroeconomic fundamental q, announced at time (minute) t. Let $E_{q, t}$ refer to the median value of the preceding market expectations for the given fundamental at announcement time $t$, and let $\hat{\sigma}_{q}$ denote the sample standard deviation of all the surprise components associated with fundamental $\mathrm{q}$. The standardized surprise of macroeconomic fundamental $\mathrm{q}$ announced at time $\mathrm{t}$ is then defined as $S_{q, t}=\left(A_{q, t}-E_{q, t}\right) / \hat{\sigma}_{q}$.

${ }^{11}$ The Bank of Japan website at www.boj.or.jp/en/theme/stat/index.htm and the Japanese Cabinet Office website at www.cao.go.jp/index-e.html provide additional details (in English) regarding the Japanese macro announcements. Details regarding the U.S. news surprises are described in Andersen et al. (2003, p. 43) and not shown here for brevity.

12 Table 1 shows considerable variation in start dates across the Japanese news variables. A similar variation is found in the start dates across the U.S. news variables analyzed in Andersen et al. (2003, p.43).

${ }^{13}$ Japanese business cycles identified using the Japanese industrial production index correlate closely with business cycles identified using the Composite Coincident Business Cycle Index from the Government of Japan Cabinet Office (“Indexes of Business Conditions"). 
each of the four U.S. and Japan business cycle combinations. As the table shows, there is no part of our sample which encompasses a Japanese upturn coincident with a U.S. downturn, i.e. our sample period encompasses only three business cycle combinations.

\section{Econometric Methodology}

We model the response of the 5-minute JPY/USD exchange rate return, $R_{t}$, as a linear function of $J$ lagged values of the return itself and $K$ lags of each of the $Q$ news variables, $S_{q, t}:$

(1) $\quad R_{t}=\beta_{0}+\sum_{j=1}^{J} \beta_{j} R_{t-j}+\sum_{q=1}^{Q} \sum_{k=0}^{K} \gamma_{q, k} S_{q, t-k}+\varepsilon_{t}, t=1, \ldots, T$

where $T=611,239, Q=35$ (19 U.S. and 16 Japanese news), and $J$ and $K$ are chosen according to the Schwarz Bayesian Information Criteria (SBIC).

We estimate Equation (1) using three different methodologies. For our baseline estimations, we only include observations within 10-minutes before and 90-minutes after each announcement. We estimate our baseline models using HAC standard errors, thus accommodating the long memory and the intraday periodicity that characterize our intraday JPY/USD exchange rate series.

The second methodology that we employ to estimate Equation (1) includes all observations in our sample. The objective is to ensure that limiting the sample to include only the 100-minute windows around the macro announcements does not affect the results. Finally, we employ the two-step weighted least squares (2WLS) estimation procedure. This approach enables us to directly estimate the volatility pattern of our data.

More specifically, in our 2WLS methodology, we first estimate Equation (1) by 
OLS and obtain the estimated residuals $\hat{\varepsilon}_{t}$. The next step is to model the volatility pattern using the absolute value of the estimated residuals of Equation (1). We follow Andersen et al. (2007) and use the following parameterization:

$$
\left|\hat{\varepsilon}_{t}\right|=\sum_{i=1}^{I^{\prime}} \beta_{i}\left|\hat{\varepsilon}_{t-i}\right|+\sum_{d=1}^{D} \gamma_{d} D_{d}+\sum_{q=1}^{Q} \sum_{j^{\prime}=0}^{J^{\prime}} \gamma_{q, j^{\prime}} D_{q, t-j^{\prime}}+u_{t}
$$

where $I^{\prime}=9$ lags of the absolute value of the estimated residuals (accounting for serial correlation, or ARCH effects), $D=38$ dummies capturing the well-documented intraday volatility pattern, and the last summation reflects dummy variables for each of the announcement surprises up to a lag length of $J^{\prime}=14$. In the last step, we use the fitted residuals from Equation (2) to perform a WLS estimation of Equation (1).

Comparing the WLS results to the results of our HAC baseline estimations ensures that there is no substantial precision lost in the coefficient estimates stemming from the baseline estimation procedure.

In order to analyze whether macro surprises have asymmetric effects across different stages of the business cycle, we first let $t_{i}$ for $i=\mathrm{A}, \ldots, \mathrm{D}$ denote each of the four possible business cycle combinations coincident for the U.S. and Japan as follows:

$-\quad t_{A}$ : Japan and U.S. upturn;

- $t_{B}$ : Japan and U.S. downturn;

$-t_{C}$ : Japan upturn and U.S. downturn;

$-t_{D}$ : Japan downturn and U.S. upturn.

We then estimate the following equation separately across the business cycle combinations during which we have a sufficient number of non-zero macro surprises to make the estimations meaningful: 


$$
R_{t}=\beta_{0}+\sum_{j=1}^{J} \beta_{j} R_{t-j}+\sum_{q=1}^{Q} \sum_{k=0}^{K} \gamma_{q, k} S_{q, t-k}+\varepsilon_{t}, \text { for } t \in t_{i} \text { and } i=\mathrm{A}, \ldots, \mathrm{D}
$$

Subsequently, we also extend our analysis to allow for the possibility that positive surprises (i.e. better than expected economic news) have a different impact than negative surprises (i.e. worse than expected economic news). We test whether this is the case by first defining $S_{q, t}^{P o s}=S_{q, t}$ if $S_{q, t} \geq 0$ (and 0 otherwise), and $S_{q, t}^{N e g}=S_{q, t}$ if $S_{q, t}<0$ (and 0 otherwise) and, in turn, estimating the following equation:

$$
R_{t}=\beta_{0}+\sum_{j=1}^{J} \beta_{j} R_{t-j}+\sum_{q=1}^{Q} \sum_{k=0}^{K} \gamma_{q, k}^{P o s} S_{q, t-k}^{P o s}+\sum_{q=1}^{Q} \sum_{k=0}^{K} \gamma_{q, k}^{N e g} S_{q, t-k}^{N e g}+\varepsilon_{t}
$$

where the superscripts Pos and Neg denote positive and negative surprises, respectively.

\section{Results}

\section{1 Country of Origin Asymmetries}

We first investigate whether similar US and Japanese macro news influences the exchange rate differently. The first column of Table 3 displays the results of our preliminary regression model described in Equation (1), including only observations within the 10-minute "windows" before and the 90-minute "windows" after each of the announcements and using HAC standard errors. We set $J=2$ and $K=0$ according to SBIC, i.e. we include as explanatory variables two lags of the exchange rate return and only the contemporaneous value of each of the 35 (19 U.S. and 16 Japanese) standardized news variables.

For the U.S. news variables our results show that 12 of the 19 variables are significant and of the correct sign. The magnitudes of the coefficient estimates suggest that news surprises regarding non-farm payroll employment and trade balance are the two 
most influential types of U.S. macro surprises. This is consistent with existing studies of U.S. macro surprises and the JPY/USD exchange rate. Furthermore, we find that a news surprise regarding GDP is the third most influential type of U.S. macro news. ${ }^{14}$

Turning to the Japanese macro news estimates from our baseline model, Table 3 shows that 6 of the 16 Japanese macro news variables are significant and of the correct sign. The two most influential Japanese news surprises are news regarding Japanese GDP (annualized) and the TANKAN large manufacturing index. According to the magnitude of the estimated coefficients, these two types of Japanese news appear less influential than news surprises regarding the two most influential types of U.S. news, but more influential than any other type of U.S. news, including news regarding U.S. GDP. ${ }^{15}$

Figures 2 and 3 display the coefficient estimates from the significant news variables for the U.S. and Japan, respectively. ${ }^{16}$

To get a sense of the relative influence of broad categories of U.S. and Japanese news, we group our news variables into seven categories and investigate the relative magnitude of the effects: GDP, real activity (RA), consumption (CONS), investment (INV), net exports (NETEX), prices (P), forward looking (FL), and monetary news (M) ${ }^{17}$.

\footnotetext{
${ }^{14}$ This is in contrast to Andersen et al. (2003) who detect no impact of U.S. GDP surprises on the JPY/USD exchange rate. However, given that our sample starts after theirs ends, it is not surprising to find some variation in the set of influential U.S. and Japanese macro news. See Faust et al. (2005) for a discussion of the time-dependence of macro news.

${ }^{15}$ Andersen et al. (2003) conjecture that their generally insignificant results regarding the influence of German news surprises on the intraday DEM/USD exchange rate may be attributable to the "uncertain", i.e. not pre-scheduled, release time of German macro announcements. By contrast, the exact timing of Japanese announcements is mostly predictable. Consequently, our significant results regarding the influence of Japanese news surprises lend some credibility to this conjecture.

${ }^{16}$ To ease the comparison of the effects of U.S. and Japanese news surprises, the coefficient estimates associated with the Japanese news in Figure 3 are multiplied by negative one.

${ }^{17}$ The groupings are as follows. GDP consists, obviously, of news regarding GDP for both the U.S. and Japan. RA consists of non-farm payroll, industrial production, capacity utilization, personal income, and consumer credit for the U.S., and large retail sales, industrial production and capacity utilization for Japan. CONS consists of consumer spending and new home sales for the U.S., and overall spending for Japan. INV consists of durable goods orders, factory orders, and business inventories for the U.S., and
} 
Figure 4 shows the average news effect for each category. The average news effect is the simple average of the significant coefficient estimates within each news category. While U.S. and Japanese GDP news, consumption news (CONS) and price news (PA) have very similar average impacts on the exchange rate, the exchange rate clearly responds respond asymmetrically depending on country of origin in regards real activity news (RA), investment news (INV), net export news (NETEX), and forward looking news (FL).

Considering the limited ability of the Bank of Japan to endogenously adjust interest rates in response to news, it is interesting to notice that forward looking news matters more when emanating from Japan. Normally, forward looking news variables are particularly likely to elicit an endogenous policy response (since monetary policy is in itself forward looking), thereby partially off-setting the exchange rate response to such news. However, as our results suggest, when the monetary authority is restricted in the extent to which it can respond to news, the exchange rate response to forward looking news is more pronounced.

The second and third columns of Table 3 display the results of our methodology robustness checks. The second column pertains to the alternative model that includes all the available data of the sample (as opposed to the baseline model which utilizes only the 100-minute windows around the announcements). The third column pertains to the WLS estimation procedure described in the previous section. Comparing the coefficient estimates across the three columns, it is evident that the results obtained using the three

construction orders for Japan. NETEX consists of trade balance for the U.S., and trade balance, current account and retail trade for Japan. P consists of producer price index and consumer price index for the U.S., and consumer price index for Japan. FL consists of consumer confidence index, NAPM index, housing starts, and index of leading indicators for the U.S., and leading economic index, consumer confidence, TANKAN large manufacturing index, and TANKAN non-manufacturing index for Japan. M consists of target federal funds rate for the U.S., and monetary base for Japan. 
different methodologies are practically identical. In other words, our methodology is proven to be very robust.

In order to get a sense of the overall explanatory power of the Japanese news surprises relative to the U.S. news surprises, we estimate Equation (1) separately with only U.S. news variables included and separately with only Japanese news variables included as explanatory variables. Table 4 presents the results. For the model including only the U.S. variables, the same 12 news variables as before are significant and of the correct sign. For the model including only the Japanese variables, the same 6 news variables as before are significant and of the correct sign. In addition, the Japanese news variable Retail Trade is now marginally significant and of the correct sign. More importantly, the $\mathrm{R}^{2}$ of the model incorporating only U.S. news variables is $11.05 \%$ while the $\mathrm{R}^{2}$ of the model incorporating only Japanese news variables is practically the same at $11.97 \%{ }^{18}$ This suggests that, overall, the Japanese macro news are as important as the U.S. macro news.

This is an interesting finding. On the one hand, our results show that focusing on only U.S. news when modeling the JPY/USD exchange rate literally misses half the story. On the other hand, our results also suggest that Japanese and U.S. news are sufficiently uncorrelated that disregarding the former does not invalidate the estimated effects of the latter, thereby confirming the results and the credibility of studies focusing on only U.S. news.

\footnotetext{
${ }^{18}$ In order to make the $\mathrm{R}^{2}$ comparison meaningful, the results displayed in Table 4 are based on time-series estimations that include all sample observations rather than the "windows" approach used for the baseline model estimations displayed in Table 3.
} 


\subsection{Business Cycle State Dependence}

There are, in principle, four possible business cycle combinations coincident for the U.S. and Japan: Japan and U.S. upturn (denoted $t_{A}$ in Equation 3); Japan and U.S. downturn (denoted $t_{B}$ in Equation 3); Japan upturn and U.S. downturn (denoted $t_{C}$ in Equation 3); and Japan downturn and U.S. upturn (denoted $t_{D}$ in Equation 3). However, as noted earlier, there is no part of our sample which encompasses a Japanese upturn coincident with a U.S. downturn $\left(t_{C}\right)$, i.e. our sample period encompasses only three business cycle combinations. Moreover, we have too few observations (non-zero news surprises) on sample $t_{B}$ (coincident U.S. and Japan downturn during April 2001 to November 2001) to carry out a meaningful model estimation. As a result, we concentrate our investigation of asymmetric effects on the remaining two business cycle combinations of Japan upturn/U.S. upturn $\left(t_{A}\right)$ and Japan downturn/U.S. upturn $\left(t_{D}\right)$.

Table 5 shows the results of the model estimated over the two different JapanU.S. business cycle combinations, as described by Equation (3). For the Japan upturn/U.S. upturn sub-sample the table shows that 10 of the U.S. news variables and 8 of the Japanese news variables are significant and of the correct sign. Again, the most influential news variables are U.S. non-farm payroll employment, U.S. trade balance, Japanese GDP, and Japanese TANKAN large manufacturing index.

The Japan downturn/U.S. upturn combination results show that only 6 of the U.S. news variables and only 3 of the Japanese news variables are significant and of the correct sign, i.e. it appears the exchange rate is responsive to a smaller set of news when

the Japanese economy is in a downturn. On the one hand, this is surprising considering that the possibility of an endogenous Japanese monetary policy response is constrained 
by the zero-interest rate bound during an economic downturn, thus we would expect macro news to have a larger intraday effect on the exchange rate during this sub-sample. On the other hand, three of the four consistently most important news variables are associated with larger coefficient estimates during the Japan downturn/U.S. upturn compared to the Japan upturn/U.S. upturn results (the exception being the Japanese TANKAN large manufacturing index).

Formal tests (t-tests) of symmetry cannot reject that the influence of any given U.S. news variable is different across the two Japan-U.S. business cycle combinations. By contrast, of the eight Japanese news variables that are significant in at least one of the two business cycle combinations, four of those (TANKAN non-manufacturing index, Construction Orders, Retail Trade, and CPI) are associated with coefficient estimates where simple t-tests reject the null of symmetry, thereby further supporting that asymmetries in the exchange rate response to Japanese news across different Japanese business cycles are present in the data. ${ }^{19}$

It is noteworthy that our data facilitates a "clean" comparison of the intraday JPY/USD exchange rate response to news across both a Japanese business cycle upturn and a Japanese business cycle downturn due to the fact that the U.S. business cycle remains the same, i.e. we vary the state of the Japanese business cycle while holding constant the state of the U.S. business cycle. ${ }^{20}$

\footnotetext{
19 The t-statistic for the null of symmetry across positive and negative $\mathrm{S}_{\mathrm{q}}$ news is given by $\left(\gamma_{\mathrm{q}}{ }^{\text {pos }}\right.$ $\left.\left.\gamma_{\mathrm{q}}{ }^{\text {neg }}\right) / \mathrm{sqrt}\left[\left(\text { s.e. } \gamma_{\mathrm{q}}{ }^{\text {pos }}\right)^{2} \text {-(s.e. } \gamma_{\mathrm{q}}{ }^{\text {neg }}\right)^{2}\right]$. T-stats discussed in this and the subsequent section are not shown for brevity but available from the authors upon request.

${ }^{20}$ As noted earlier, we do not have the data necessary for testing whether the described variation in exchange rate responses across the Japanese business cycle is contingent on a U.S. business cycle upturn or if our results are applicable regardless of the state of the U.S. economy.
} 


\subsection{Asymmetric Responses to Positive and Negative Surprises}

As noted earlier, other studies generally find some evidence of asymmetric responses to U.S. news surprises. In particular, negative surprises about the U.S. economy tend to have a greater impact than positive surprises. In this section we analyze whether the same result holds true for Japanese news surprises during the zero interest rate period. In order to do so, we estimate Equation (4), which, as previously noted, is an extension of our regression model that allows positive surprises to have a different coefficient estimate than negative surprises. We expect a greater impact when Japanese news is "bad" given the limited scope for conducting counter-cyclical actions to offset the news effect on the economy (and the exchange rate) during the zero-interest rate period. Table 6 presents the results.

Contrary to our priors, the asymmetries across positive and negative Japanese news surprises appear very modest and unsystematic. We find an equal number of significant coefficients of the expected sign associated with negative and positive Japanese surprises ( 7 of each). The average absolute economic impacts of negative and positive Japanese surprises are practically identical (0.0365 for negative Japanese surprises versus 0.0370 for positive ones). Three Japanese news variables (Monetary Base, Retail Trade, and Overall Spending) are associated with coefficient estimates where formal tests (t-tests) reject the null of symmetry across the positive versus negative news surprises. However, only in the case of Retail Trade news is the effect (in absolute terms) of negative news larger than that of positive news. Overall, these results do not support the idea that the exchange rate responds asymmetrically across "good" and "bad" Japanese news. 
Consistent with other studies, however, we do find some evidence that negative surprises about the U.S. economy tend to have larger effects than positive U.S. surprises. There are slightly more significant coefficients of the expected sign associated with negative U.S. surprises than with positive surprises (11 versus 9). The average absolute effect of a negative U.S. surprise is 0.0403 compared to the average absolute effect of a positive surprise is 0.0342 . Three U.S. news variables (GDP, CPI, and Housing Starts) are associated with coefficient estimates where t-tests reject the null of symmetry across the (in absolute terms) smaller effect of positive versus negative news surprises.

\section{Conclusion}

Our investigation considers possible asymmetric responses of the intraday exchange rate to macroeconomic news announcements. We address this issue by jointly investigating the intraday JPY/USD exchange rate responses to U.S. and Japanese macroeconomic news surprises over the 1 January 1999 to 31 October 2006 time-period. Asymmetric exchange rate responses to news seem particularly likely to appear in economic and institutional settings such as the zero interest rate environment of Japan. When lower interest rates (below zero) are not feasible, endogenous policy reactions to macroeconomic shocks are constrained. Given the close linkages between interest rates and exchange rates, these constraints, in turn, are likely to make the exchange rate response to news asymmetric.

We discuss several asymmetries that may occur during the Japanese zero interest rate regime. First, we consider whether U.S. and Japanese macro news influence the exchange rate differently. Our results show that for several types of news the exchange 
rate responds asymmetrically depending on country origin of news. Consistent with our priors, we find that forward-looking news is especially important when emanating from the country where the monetary authority is restricted in the extent to which it can respond to shocks. We also compare the overall influence of Japanese news to the overall influence of U.S. news, and we show that Japanese macro news are as important as U.S. macro news in influencing the JPY/USD exchange rate.

Second, we consider whether the exchange rate effects of news surprises vary with different stages of the business cycle. Our results provide evidence of asymmetries in the exchange rate response to Japanese news across different Japanese business cycle stages, consistent with the idea that an institutional setting that limits the possibility of endogenous policy responses to news makes asymmetries more likely.

Third, we investigate whether "good" and "bad" news exert similar intraday effects (in absolute terms) on the exchange rate. We find no clear evidence of asymmetric effects across positive and negative Japanese news surprises. This is a surprising finding, considering that endogenous policy responses to positive Japanese news are possible while endogenous policy responses to negative Japanese news are not.

By contrast, we find some evidence of asymmetric effects across positive and negative U.S. news surprises. This finding is not in itself surprising as it conforms with the existing literature on U.S. news and exchange rates. However, in light of the previous finding - that positive-negative asymmetries are not present in the Japanese news even though such asymmetries would seem particularly likely during the zero interest rate period under study - this could indicate that asymmetries in regards to positive versus negative news particularly pertains to U.S. news. Additional research investigating 
exchange rate responses to both positive and negative U.S. and non-U.S. news in other currency markets is warranted in order to address whether this is generally the case.

Overall our results illustrate the necessity of taking into account the country of origin of news, business cycle asymmetries, and the direction of news, in order to more accurately assess the intraday exchange rate responses to macroeconomic news surprises. This seems particularly important in contexts where institutional settings limit the endogenous policy response to news. 


\section{References}

Almeida, Alvaro; Charles Goodhart and Richard Payne (1998): "The Effects of Macroeconomic News on High Frequency Exchange Rate Behavior", Journal of Financial and Quantitative Analysis 33, 383-408.

Andersen, Torben G. and Tim Bollerslev (1998): "Deutsche Mark-Dollar Volatility: Intraday Activity Patterns, Macroeconomic Announcements, and Longer-Run Dependencies", Journal of Finance 53, 219-265.

Andersen, Torben G.; Tim Bollerslev; Francis X. Diebold and Clara Vega (2003): "Micro Effects of Macro Announcements: Real-Time Price Discovery in Foreign Exchange", American Economic Review 93, 38-62.

Andersen, Torben G.; Tim Bollerslev; Francis X. Diebold and Clara Vega (2007): "RealTime Price Discovery in Global Stock, Bond and Foreign Exchange Markets", Journal of International Economics 73, 251-277.

Basistha, Arabinda and Alexander Kurov (2008): "Macroeconomic cycles and the stock market's reaction to monetary policy," Journal of Banking and Finance 32, 2606-2616.

Bauwens, Luc; Ben Omrane, Walid and Pierre Giot (2005): "News Announcements, Market Activity and Volatility in the Euro/Dollar Foreign Exchange Market", Journal of International Money and Finance 24, 1108-1125.

Bollerslev, Tim and Ian Domowitz (1993): "Trading Patterns and Prices in the Interbank Foreign Exchange Market”, Journal of Finance 48, 1421-1443.

Cai, Jun; Yan-Leung Cheung; Raymond S.K. Lee and Michael Melvin (2001): "Once-InA-Generation' Yen Volatility in 1998: Fundamentals, Intervention, and Order Flow", Journal of International Money and Finance 20, 327-347.

Chaboud, Alain P.; Sergey V. Chernenko; Edward Howorka; Raj S. Krishnasmi Iyer; David Liu and Jonathan H. Wright (2004): "The High-Frequency Effects of U.S. Macroeconomic Data Releases on Prices and Trading Activity in the Global Interdealer Foreign Exchange Market", Board of Governors of the Federal Reserve System, International Finance Discussion Papers No. 823.

Clarida, Richard and Daniel Waldman (2007): "Is Bad News about Inflation Good News for the Exchange Rate?", NBER Working Paper No. 13010.

Dacorogna, Michel M.; Ulrich A. Müller; Robert J. Nagler; Richard B. Olsen and Olivier V. Pictet (1993): "A Geographical Model for the Daily and Weekly Seasonal Volatility in the Foreign Exchange Market", Journal of International Money and Finance 12, 413-438. 
Dominguez, Kathryn; and Freyan Panthaki (2006): "What Defines 'News' in Foreign Exchange Markets?”, Journal of International Money and Finance 25, 168-198.

Engel, Charles; Nelson C. Mark and Kenneth D. West (2007): "Exchange Rate Models Are Not as Bad as You Think", NBER Working Paper No. 13318.

Fatum, Rasmus and Barry Scholnick (2008): "Monetary Policy News and Exchange Rate Responses: Do Only Surprises Matter?, Journal of Banking and Finance, 32, 1076-1086.

Faust, Jon; John H. Rogers; Shing-Yi Wang and Jonathan H. Wright (2005): “The HighFrequency Response of Exchange Rates and Interest Rates to Macroeconomic Announcements", Journal of Monetary Economics 54, 1051-1068.

Flannery, Mark and Aris A. Protopapadakis (2002): "Macroeconomic Factors Do Influence Aggregate Stock Returns", The Review of Financial Studies, 15 (3), 751-782.

Goodhart, Charles; Takatoshi Ito and Richard Payne (1996): "One Day in June 1993: A Study of the Working of the Reuters 2000-2 Electronic Foreign Exchange Trading System" in Jeffrey A. Frankel; Giampaolo Galli and Alberto Giovannini, eds., The Microstructure of Foreign Exchange Markets, 107-179. University of Chicago Press, Chicago.

Ito, Takatoshi and V. Vance Roley (1987): "News from the U.S. and Japan. Which Moves the Yen/Dollar Exchange Rate?”, Journal of Monetary Economics 19, 255-277.

McQueen, Grant and V. Vance Roley (1993): "Stock Prices, News, and Business Conditions", Review of Financial Studies 6, 683-707.

Melvin, Michael and Xixi Yin (2000): "Public Information Arrival, Exchange Rate Volatility, and Quote Frequency," The Economic Journal 110, 644-661. 
Table 1: Japanese Macro Surprises

\begin{tabular}{|c|c|c|c|c|}
\hline Announcement & $\begin{array}{l}\text { Non-Zero } \\
\text { Announcement } \\
\text { Surprises }\end{array}$ & $\begin{array}{l}\text { Starting } \\
\text { Date }\end{array}$ & $\begin{array}{l}\text { Announcement } \\
\text { Frequency }\end{array}$ & $\begin{array}{l}\text { Announcement } \\
\text { Time (Tokyo } \\
\text { Time) }\end{array}$ \\
\hline \multicolumn{5}{|l|}{ GDP } \\
\hline GDP Quarterly & 39 & $03 / 12 / 99$ & Quarterly & Irregular \\
\hline GDP Annually & 25 & $09 / 17 / 03$ & Quarterly & $8.50 \mathrm{AM}$ \\
\hline \multicolumn{5}{|l|}{ Real Activity } \\
\hline Large Retail Sales & 78 & $12 / 15 / 99$ & Monthly & $8.50 \mathrm{AM}$ \\
\hline Industrial Production & 116 & $05 / 17 / 00$ & Monthly & Irregular \\
\hline Capacity Utilization & 53 & $03 / 15 / 02$ & Monthly & $1.30 \mathrm{PM}$ \\
\hline \multicolumn{5}{|l|}{ Consumption } \\
\hline Overall Spending & 7 & $03 / 31 / 06$ & Monthly & $8.50 \mathrm{AM}$ \\
\hline \multicolumn{5}{|l|}{ Investment } \\
\hline Construction Orders & 75 & $03 / 01 / 00$ & Monthly & $2.00 \mathrm{PM}$ \\
\hline \multicolumn{5}{|l|}{ Net exports } \\
\hline Trade Balance & 34 & $09 / 12 / 02$ & Monthly & $8.50 \mathrm{AM}$ \\
\hline Current Account & 79 & $01 / 18 / 99$ & Monthly & $8.50 \mathrm{AM}$ \\
\hline Retail Trade & 60 & $02 / 26 / 01$ & Monthly & Irregular \\
\hline \multicolumn{5}{|l|}{ Prices } \\
\hline Consumer Price Index & 37 & $09 / 28 / 01$ & Monthly & Irregular \\
\hline \multicolumn{5}{|l|}{ Forward Looking } \\
\hline Leading Economic Index & 73 & $12 / 06 / 99$ & Monthly & $2.00 \mathrm{PM}$ \\
\hline Consumer Confidence Index & 42 & $03 / 23 / 02$ & Monthly & Irregular \\
\hline TANKAN Large Manufacturing & 17 & $12 / 12 / 01$ & Quarterly & $8.50 \mathrm{AM}$ \\
\hline TANKAN Non-Manufacturing & 14 & $04 / 01 / 02$ & Quarterly & Irregular \\
\hline \multicolumn{5}{|l|}{ Monetary Policy } \\
\hline Monetary Base & 45 & $10 / 02 / 02$ & Monthly & $8.50 \mathrm{AM}$ \\
\hline
\end{tabular}

Notes:

a) Data Sources: Bank of Japan, Japanese Cabinet Office, and Bloomberg News Service

b) Sample period: 1 January 1999 to 31 October 2006

c) While our sample period starts 1 January 1999, some of the announcement series under study are not tracked by Bloomberg News Service and/or data on surveys of market expectations are not available until later in the sample. The starting date denotes when the first announcement and associated survey are available for a given announcement series. The announcement time of an announcement is denoted irregular if the announcement time changes during the sample period.

d) Additional details are available from the authors upon request. 
Table 2: U.S. and Japanese Business Cycle Combinations

\begin{tabular}{|l|l|l|l|}
\hline $\begin{array}{l}\text { Business Cycle } \\
\text { Combination }\end{array}$ & $\begin{array}{l}\text { Japanese } \\
\text { Business Cycle }\end{array}$ & $\begin{array}{l}\text { U.S. } \\
\text { Business Cycle }\end{array}$ & Dates \\
\hline \multicolumn{5}{|l|}{} \\
\hline A & Upturn & Upturn & January 1999 to December 2000 \\
\hline \multicolumn{5}{|l|}{} \\
\hline & Upturn & Upturn & February 2002 to October 2006 \\
\hline B & Upturn & No observations \\
\hline \multicolumn{5}{|l|}{} \\
\hline C & Downturn & Upturn & January 2001 to March 2001 \\
\hline & Downturn & Upturn & December 2001 to January 2002 \\
\hline \multicolumn{3}{|l|}{} \\
\hline D & Downturn & Downturn & April 2001 to November 2001 \\
\hline & & &
\end{tabular}

Notes:

a) U.S. business cycle definitions in accordance with the Business Cycle Dating Committee of the National Bureau of Economic Research.

b) Japanese business cycle definitions based on the Japanese industrial production index and the Composite Coincident Business Cycle Index of the Government of Japan Cabinet Office. 
Table 3: Preliminary Regression with Three Different Methodologies

Sample:

Estimation Procedure:

\begin{tabular}{l} 
U.S. Announcements \\
\hline GDP \\
Nonfarm payroll employment \\
Industrial production \\
Capacity utilization \\
Personal income \\
Consumer credit \\
Consumer spending \\
New home sales \\
Durable goods orders \\
Factory orders \\
Business inventories \\
Trade balance \\
Producer price index \\
Consumer price index \\
Consumer confidence index \\
NAPM index \\
Housing starts \\
Index of leading indicators \\
Target federal funds rate
\end{tabular}

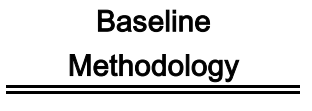

100-min. windows

\begin{tabular}{cc} 
Coef. & S.E. \\
\hline $0.0410^{* * *}(0.0056)$
\end{tabular}

$0.1172^{* * *}(0.0207)$

$0.0066 \quad(0.0052)$

0.0122 ** $(0.0057)$

$0.0034 \quad(0.0034)$

$-0.0029 \quad(0.0018)$

0.0122 *** $(0.0041)$

0.0103 * $(0.0053)$

0.0235 *** $(0.0064)$

$0.0036 \quad(0.0056)$

$-0.0046 \quad(0.0039)$

0.0739 *** $(0.0109)$

0.0094 ** $(0.0046)$

$0.0042 \quad(0.0067)$

$0.0363^{* * *}(0.0049)$

$0.0329 * * * \quad(0.0050)$

0.0083 ** (0.0039)

$0.0090 * * \quad(0.0037)$

$-0.0009^{* * *}(0.0001)$

Trade balance
Current account
Leading economic index
Consumer confidence index
TANKAN large manufacturing index
TANKAN non-manufacturing index
Monetary base
Capacity utilization
GDP (quarterly)
GDP (annual)
Large retail sales
Construction orders
Industrial production
Retail trade
Consumer price index
Overall spending

R-squared:

Number of observations:
OLS with HAC S.E.

$\frac{\begin{array}{c}\text { Methodology } \\ \text { Check } 1\end{array}}{\text { All sample }}$

\begin{tabular}{cc} 
Coef. & S.E. \\
\hline $0.0415^{* * *}(0.0055)$
\end{tabular}

$0.1179^{* * *}(0.0207)$

$0.0071 \quad(0.0051)$

$0.0121^{* *}(0.0057)$

$0.0033 \quad(0.0034)$

$-0.0028 \quad(0.0018)$

$0.0122^{* * *}(0.0041)$

$0.0103^{* *}(0.0052)$

$0.0241^{* * *}(0.0065)$

$0.0043 \quad(0.0056)$

$-0.0042 \quad(0.0039)$

$0.0741^{* * *}(0.0107)$

0.0091 * $(0.0046)$

$0.0043 \quad(0.0067)$

$0.0327^{* * *}(0.0050)$

0.0080 ** $(0.0039)$

$0.0089^{* *}(0.0036)$

$-0.0016^{* * *}(0.0000)$

\begin{tabular}{cc} 
Coef. & S.E. \\
\hline-0.0053 & $(0.0038)$ \\
-0.0047 & $(0.0037)$ \\
0.0016 & $(0.0045)$ \\
0.0038 & $(0.0037)$ \\
$-0.0611 * * *$ & $(0.0176)$ \\
-0.0083 & $(0.0131)$ \\
-0.0047 & $(0.0040)$ \\
-0.0070 & $(0.0116)$ \\
$-0.0239 * * *$ & $(0.0067)$ \\
$-0.0635 * * *$ & $(0.0189)$ \\
0.0013 & $(0.0039)$ \\
-0.0019 & $(0.0042)$ \\
$-0.0191 * * *$ & $(0.0033)$ \\
-0.0108 & $(0.0066)$ \\
$-0.0087 * * *$ & $(0.0029)$ \\
$-0.0077 * * *$ & $(0.0028)$ \\
\hline
\end{tabular}

$11.19 \%$

33,466
$0.0369 * * *(0.0050)$

\begin{tabular}{|c|c|}
\hline \multicolumn{2}{|c|}{$\begin{array}{c}\text { Methodology } \\
\text { Check } 2\end{array}$} \\
\hline \multicolumn{2}{|c|}{$\begin{array}{l}\text { 100-min. windows } \\
\text { WLS }\end{array}$} \\
\hline Coef. & S.E. \\
\hline $0.0397^{* * *}$ & $(0.0037)$ \\
\hline $0.1193^{* * *}$ & $(0.0043)$ \\
\hline 0.0077 & $(0.0054)$ \\
\hline 0.0121 * & $(0.0069)$ \\
\hline 0.0030 & $(0.0035)$ \\
\hline-0.0024 & \\
\hline $0.0117^{* * *}$ & $(0.0037)$ \\
\hline $0.0097^{* * *}$ & $(0.0036)$ \\
\hline $0.0237^{* * *}$ & $(0.0038)$ \\
\hline 0.0039 & $(0.0038)$ \\
\hline-0.0043 & $(0.0037)$ \\
\hline $0.0716^{* * *}$ & $(0.0045)$ \\
\hline $0.0097^{* * *}$ & $(0.0037)$ \\
\hline 0.0045 & $(0.0037)$ \\
\hline $0.0366^{* * *}$ & $(0.0038)$ \\
\hline 0.0332 *** & $(0.0036)$ \\
\hline 0.0094 ** & $(0.0037)$ \\
\hline 0.0093 ** & $(0.0037)$ \\
\hline-0.0009 & $(0.0067)$ \\
\hline
\end{tabular}

\begin{tabular}{|c|c|c|c|}
\hline Coef. & S.E. & Coef. & S.E. \\
\hline-0.0056 & $\overline{(0.0038)}$ & -0.0052 & $(0.0065)$ \\
\hline-0.0049 & (0.0037) & -0.0048 & $(0.0042)$ \\
\hline 0.0014 & $(0.0043)$ & 0.0000 & $(0.0036)$ \\
\hline 0.0035 & $(0.0036)$ & 0.0028 & $(0.0056)$ \\
\hline$-0.0618 * * *$ & (0.0175) & -0.0576 *** & (0.0077) \\
\hline-0.0085 & (0.0131) & -0.0063 & $(0.0079)$ \\
\hline-0.0043 & (0.0038) & -0.0044 & (0.0053) \\
\hline-0.0065 & (0.0112) & -0.0038 & (0.0135) \\
\hline-0.0235 *** & (0.0065) & $-0.0231^{* * *}$ & (0.0078) \\
\hline$-0.0647^{* * *}$ & $(0.0187)$ & $-0.0639 * * *$ & $(0.0105)$ \\
\hline 0.0013 & $(0.0038)$ & 0.0009 & $(0.0043)$ \\
\hline-0.0019 & (0.0040) & -0.0014 & (0.0073) \\
\hline$-0.0186 * * *$ & $(0.0032)$ & $-0.0178 * * *$ & $(0.0030)$ \\
\hline-0.0099 & $(0.0064)$ & -0.0077 & $(0.0055)$ \\
\hline$-0.0084 * * *$ & $(0.0029)$ & $-0.0091 * *$ & $(0.0044)$ \\
\hline$-0.0069^{* *}$ & $(0.0029)$ & -0.0078 & $(0.0117)$ \\
\hline \multicolumn{2}{|c|}{$3.80 \%$} & \multicolumn{2}{|c|}{$10.48 \%$} \\
\hline \multicolumn{2}{|c|}{611,237} & \multicolumn{2}{|c|}{33,466} \\
\hline
\end{tabular}

Statistics associated with the constant and the first two lags of the dependent variable are omitted for space considerations and are available upon request. Standard errors are given in parenthesis. The symbols *, **, and $* * *$ denote that the individual coefficient is significant at the $10 \%, 5 \%$, and $1 \%$ significance level respectively. 
Table 4: U.S. Macro Surprises Only and Japanese Macro Surprises Only Regressions

Sample:

Estimation Procedure:

U.S. Announcements

Nonfarm payroll employment

Industrial production

Capacity utilization

Personal income

Consumer credit

Consumer spending

New home sales

Durable goods orders

Factory orders

Business inventories

Trade balance

Producer price index

Consumer price index

Consumer confidence index

NAPM index

Housing starts

Index of leading indicators

Target federal funds rate

\begin{tabular}{l}
\multicolumn{1}{c}{ Japanese Announcements } \\
\hline Trade balance \\
Current account \\
Leading economic index \\
Consumer confidence index \\
TANKAN large manufacturing index \\
TANKAN non-manufacturing index \\
Monetary base \\
Capacity utilization \\
GDP (quarterly) \\
GDP (annual) \\
Large retail sales \\
Construction orders \\
Industrial production \\
Retail trade \\
Consumer price index \\
Overall spending \\
\hline
\end{tabular}

R-squared:

Number of observations:

\begin{tabular}{|c|c|c|c|}
\hline \multicolumn{2}{|c|}{$\begin{array}{l}\text { U.S. } \\
\text { Only }\end{array}$} & \multicolumn{2}{|c|}{$\begin{array}{c}\text { Japanese } \\
\text { Only }\end{array}$} \\
\hline \multicolumn{2}{|c|}{ 100-min. windows } & \multicolumn{2}{|c|}{ 100-min. windows } \\
\hline \multicolumn{2}{|c|}{ OLS with HAC S.E. } & \multicolumn{2}{|c|}{ OLS with HAC S.E. } \\
\hline Coef. & S.E. & Coef. & S.E. \\
\hline $0.0411^{* * *}$ & $(0.0056)$ & - & - \\
\hline $0.1171^{* * *}$ & $(0.0207)$ & - & - \\
\hline 0.0066 & $(0.0052)$ & - & - \\
\hline $0.0122 * *$ & $(0.0057)$ & - & - \\
\hline 0.0035 & $(0.0034)$ & - & - \\
\hline-0.0029 & $(0.0018)$ & - & - \\
\hline $0.0122 * * *$ & $(0.0041)$ & - & - \\
\hline $0.0104^{* *}$ & $(0.0053)$ & - & - \\
\hline $0.0235^{* * *}$ & $(0.0064)$ & - & - \\
\hline 0.0037 & $(0.0056)$ & - & - \\
\hline-0.0046 & $(0.0039)$ & - & - \\
\hline $0.0739^{* * *}$ & $(0.0109)$ & - & - \\
\hline $0.0094^{* *}$ & $(0.0046)$ & - & - \\
\hline 0.0042 & $(0.0067)$ & - & - \\
\hline $0.0363^{* * *}$ & $(0.0049)$ & - & - \\
\hline $0.0329 * * *$ & $(0.0050)$ & - & - \\
\hline $0.0083^{* *}$ & $(0.0039)$ & - & - \\
\hline $0.0090 * *$ & $(0.0037)$ & - & - \\
\hline$-0.0010^{* * *}$ & $(0.0001)$ & - & - \\
\hline Coef. & S.E. & Coef. & S.E. \\
\hline- & - & -0.0052 & $(0.0038)$ \\
\hline- & - & -0.0049 & $(0.0037)$ \\
\hline- & - & 0.0016 & $(0.0045)$ \\
\hline- & - & 0.0039 & $(0.0037)$ \\
\hline- & - & $-0.0611^{* * *}$ & $(0.0175)$ \\
\hline- & - & -0.0084 & $(0.0131)$ \\
\hline- & - & -0.0046 & $(0.0041)$ \\
\hline- & - & -0.0071 & $(0.0119)$ \\
\hline - & - & $-0.0243 * * *$ & $(0.0067)$ \\
\hline- & - & $-0.0630^{* * *}$ & $(0.0188)$ \\
\hline- & - & 0.0013 & $(0.0040)$ \\
\hline- & - & -0.0017 & $(0.0043)$ \\
\hline- & - & $-0.0189 * * *$ & $(0.0034)$ \\
\hline- & - & $-0.0111 *$ & $(0.0066)$ \\
\hline- & - & $-0.0089 * * *$ & $(0.0029)$ \\
\hline- & - & $-0.0075^{* * *}$ & $(0.0028)$ \\
\hline 11.05 & & 11.97 & \\
\hline 24,9 & & 8,54 & \\
\hline
\end{tabular}

Statistics associated with the constant and the first two lags of the dependent variable are omitted for space considerations and are available upon request. Standard errors are given in parenthesis. The symbols *, **, and *** denote that the individual coefficient is significant at the $10 \%, 5 \%$, and $1 \%$ significance level respectively. 
Table 5: Business Cycle Effects

Sample:

Estimation Procedure:

\begin{tabular}{l} 
U.S. Announcements \\
\hline GDP \\
Nonfarm payroll employment \\
Industrial production \\
Capacity utilization \\
Personal income \\
Consumer credit \\
Consumer spending \\
New home sales \\
Durable goods orders \\
Factory orders \\
Business inventories \\
Trade balance \\
Producer price index \\
Consumer price index \\
Consumer confidence index \\
NAPM index \\
Housing starts \\
Index of leading indicators \\
Target federal funds rate \\
Japanese Announcements
\end{tabular}

Trade balance

Current account

Leading economic index

Consumer confidence index

TANKAN large manufacturing index

TANKAN non-manufacturing index

Monetary base

Capacity utilization

GDP (quarterly)

GDP (annual)

Large retail sales

Construction orders

Industrial production

Retail trade

Consumer price index

Overall spending

\section{Japan Upturn and U.S. Upturn}

100-min. windows

OLS with HAC S.E.

\begin{tabular}{cc} 
Coef. & S.E. \\
\hline $0.0470^{* * *}$ & $(0.0073)$
\end{tabular}

$0.1210^{* * *}(0.0324)$

$0.0054 \quad(0.0069)$

$0.0117 \quad(0.0082)$

$0.0055 *(0.0031)$

$-0.0043 *(0.0026)$

$0.0137^{* *}(0.0053)$

$0.0114 \quad(0.0075)$

$0.0294^{* * *}(0.0085)$

$0.0035 \quad(0.0090)$

$-0.0053 \quad(0.0050)$

$0.0624^{* * *}(0.0082)$

0.0094 * $(0.0052)$

$-0.0055 \quad(0.0081)$

$0.0386^{* * *}(0.0069)$

$0.0327^{* * *}(0.0068)$

$0.0090 * \quad(0.0053)$

$0.0084 \quad(0.0068)$

$-0.0008^{* * *}(0.0001)$

\begin{tabular}{cc} 
Coef. & S.E. \\
\hline-0.0033 & $(0.0036)$ \\
-0.0038 & $(0.0046)$ \\
0.0002 & $(0.0031)$ \\
0.0005 & $(0.0050)$ \\
$-0.0981 * * *$ & $(0.0327)$ \\
$-0.0338 * *$ & $(0.0133)$ \\
-0.0037 & $(0.0044)$ \\
-0.0067 & $(0.0048)$ \\
$-0.0210 * *$ & $(0.0060)$ \\
$-0.0430 * *$ & $(0.0214)$ \\
0.0050 & $(0.0059)$ \\
$-0.0106 * * *$ & $(0.0021)$ \\
$-0.0182 * * *$ & $(0.0036)$ \\
$-0.0158 *$ & $(0.0082)$ \\
$-0.0108 * * *$ & $(0.0035)$ \\
-0.0070 & $(0.0095)$ \\
\hline & $11.30 \%$ \\
19,473
\end{tabular}

\begin{tabular}{cc}
\multicolumn{2}{c}{ Japan Downturn } \\
and U.S. Upturn \\
\hline \hline \multicolumn{2}{c}{ 100-min. windows } \\
OLS with HAC S.E. \\
\hline Coef. & S.E. \\
\hline $0.0319 * * *$ & $(0.0083)$ \\
$0.1891 * * *$ & $(0.0298)$ \\
0.0055 & $(0.0200)$ \\
0.0190 & $(0.0162)$ \\
-0.0044 & $(0.0123)$ \\
-0.0025 & $(0.0033)$ \\
0.0092 & $(0.0081)$ \\
0.0028 & $(0.0063)$ \\
0.0163 & $(0.0137)$ \\
0.0081 & $(0.0070)$ \\
-0.0073 & $(0.0109)$ \\
$0.0889 * * *$ & $(0.0219)$ \\
0.0042 & $(0.0114)$ \\
0.0132 & $(0.0140)$ \\
$0.0269 * *$ & $(0.0134)$ \\
$0.0206 * *$ & $(0.0086)$ \\
0.0079 & $(0.0062)$ \\
$0.0139 * *$ & $(0.0064)$ \\
- & -
\end{tabular}

\begin{tabular}{cc} 
Coef. & S.E. \\
\hline-0.0178 & $(0.0118)$ \\
-0.0111 & $(0.0076)$ \\
0.0018 & $(0.0057)$ \\
0.0070 & $(0.0055)$ \\
$-0.0635 * * *$ & $(0.0186)$ \\
0.0247 & $(0.0247)$ \\
-0.0028 & $(0.0092)$ \\
-0.0077 & $(0.0148)$ \\
-0.0223 & $(0.0144)$ \\
$-0.0835 * * *$ & $(0.0272)$ \\
0.0009 & $(0.0113)$ \\
$0.0082 * *$ & $(0.0038)$ \\
$-0.0236 * * *$ & $(0.0084)$ \\
0.0064 & $(0.0084)$ \\
-0.0014 & $(0.0035)$ \\
- & - \\
\hline \multicolumn{2}{|c}{$13.11 \%$} \\
8,709
\end{tabular}

Statistics associated with the constant and the first two lags of the dependent variable are omitted for space considerations and are available upon request. Standard errors are given in parenthesis. The symbols $*, * *$, and $* * *$ denote that the individual coefficient is significant at the $10 \%, 5 \%$, and $1 \%$ significance level respectively. 
Table 6: Positive and Negative Macro Surprises

\begin{tabular}{|c|c|c|c|c|}
\hline \multirow{3}{*}{$\begin{array}{l}\text { Sample: } \\
\text { Estimation Procedure: } \\
\text { U.S. Announcements }\end{array}$} & \multicolumn{2}{|c|}{$\begin{array}{c}\text { Postive } \\
\text { Surprises }\end{array}$} & \multicolumn{2}{|c|}{$\begin{array}{l}\text { Negative } \\
\text { Surprises }\end{array}$} \\
\hline & \multicolumn{4}{|c|}{$\begin{array}{l}\text { 100-min. windows } \\
\text { OLS with HAC S.E. }\end{array}$} \\
\hline & Coef. & S.E. & Coef. & S.E. \\
\hline GDP & 0.0219 *** & $\overline{(0.0049)}$ & $0.0612^{\star * \star}$ & $(0.0085)$ \\
\hline Nonfarm payroll employment & $0.1111^{\star \star \star}$ & $(0.0209)$ & $0.1193^{* \star \star}$ & $(0.0271)$ \\
\hline Industrial production & 0.0122 & $(0.0076)$ & 0.0017 & $(0.0077)$ \\
\hline Capacity utilization & 0.0093 & $(0.0086)$ & 0.0154 * & $(0.0083)$ \\
\hline Personal income & $0.0045 *$ & $(0.0025)$ & 0.0008 & $(0.0107)$ \\
\hline Consumer credit & -0.0007 & $(0.0018)$ & $-0.0055 *$ & $(0.0031)$ \\
\hline Consumer spending & 0.0081 & $(0.0052)$ & 0.0176 ** & $(0.0073)$ \\
\hline New home sales & 0.0080 & $(0.0056)$ & 0.0147 & $(0.0111)$ \\
\hline Durable goods orders & 0.0153 * & $(0.0090)$ & $0.0337^{* * *}$ & $(0.0069)$ \\
\hline Factory orders & $0.0129^{* * *}$ & $(0.0044)$ & -0.0063 & $(0.0101)$ \\
\hline Business inventories & $-0.0105 *$ & $(0.0054)$ & 0.0022 & $(0.0057)$ \\
\hline Trade balance & $0.0633^{* * *}$ & $(0.0103)$ & $0.0794^{* * *}$ & $(0.0153)$ \\
\hline Producer price index & 0.0049 & $(0.0049)$ & $0.0154 *$ & $(0.0081)$ \\
\hline Consumer price index & -0.0111 & $(0.0098)$ & 0.0144 * & $(0.0078)$ \\
\hline Consumer confidence index & $0.0377^{* * *}$ & $(0.0071)$ & $0.0345^{* * *}$ & $(0.0068)$ \\
\hline NAPM index & $0.0326 * * *$ & $(0.0076)$ & $0.0330 * * *$ & $(0.0073)$ \\
\hline Housing starts & 0.0026 & $(0.0048)$ & $0.0196 * * *$ & $(0.0054)$ \\
\hline Index of leading indicators & 0.0083 ** & $(0.0039)$ & 0.0098 & $(0.0073)$ \\
\hline Target federal funds rate & $-0.0009 * * *$ & $(0.0001)$ & $-0.0009 * * *$ & $(0.0001)$ \\
\hline Japanese Announcements & Coef. & S.E. & Coef. & S.E. \\
\hline Trade balance & -0.0036 & $(0.0076)$ & -0.0056 & $(0.0042)$ \\
\hline Current account & -0.0078 & $(0.0049)$ & 0.0000 & $(0.0069)$ \\
\hline Leading economic index & 0.0055 & $(0.0049)$ & -0.0039 & $(0.0031)$ \\
\hline Consumer confidence index & 0.0051 & $(0.0061)$ & 0.0030 & $(0.0045)$ \\
\hline TANKAN large manufacturing index & $-0.0591 *$ & $(0.0318)$ & $-0.0694^{* * *}$ & $(0.0231)$ \\
\hline TANKAN non-manufacturing index & -0.0058 & $(0.0295)$ & -0.0117 & $(0.0157)$ \\
\hline Monetary base & $-0.0199 * * *$ & $(0.0074)$ & -0.0020 & $(0.0044)$ \\
\hline Capacity utilization & $-0.0196^{* * *}$ & $(0.0058)$ & 0.0082 & $(0.0181)$ \\
\hline GDP (quarterly) & $-0.0219 * * *$ & $(0.0059)$ & $-0.0317^{*}$ & $(0.0180)$ \\
\hline GDP (annual) & $-0.0465 * *$ & $(0.0182)$ & $-0.0773^{* * *}$ & $(0.0283)$ \\
\hline Large retailers sales & -0.0049 & $(0.0043)$ & 0.0071 & $(0.0053)$ \\
\hline Construction orders & -0.0032 & $(0.0047)$ & -0.0014 & $(0.0054)$ \\
\hline Industrial production & -0.0182 ** & $(0.0074)$ & $-0.0195 * * *$ & $(0.0037)$ \\
\hline Retail trade & 0.0012 & $(0.0046)$ & $-0.0398^{* * *}$ & $(0.0135)$ \\
\hline Consumer price index & -0.0062 & $(0.0038)$ & -0.0108 ** & $(0.0046)$ \\
\hline Overall spending & $-0.0735^{\star * *}$ & $(0.0197)$ & $-0.0071^{* *}$ & $(0.0028)$ \\
\hline & & & & \\
\hline Number of observations: & & & & \\
\hline
\end{tabular}

Both sets of coefficients are based on the same regression. Standard errors are given in parenthesis. The symbols *,**, and *** denote either that (1) the individual coefficient is significant or (2) the null hypothesis is rejected at the $10 \%, 5 \%$, and $1 \%$ significance level respectively. 
Figure 1: Money Market Rate in Japan

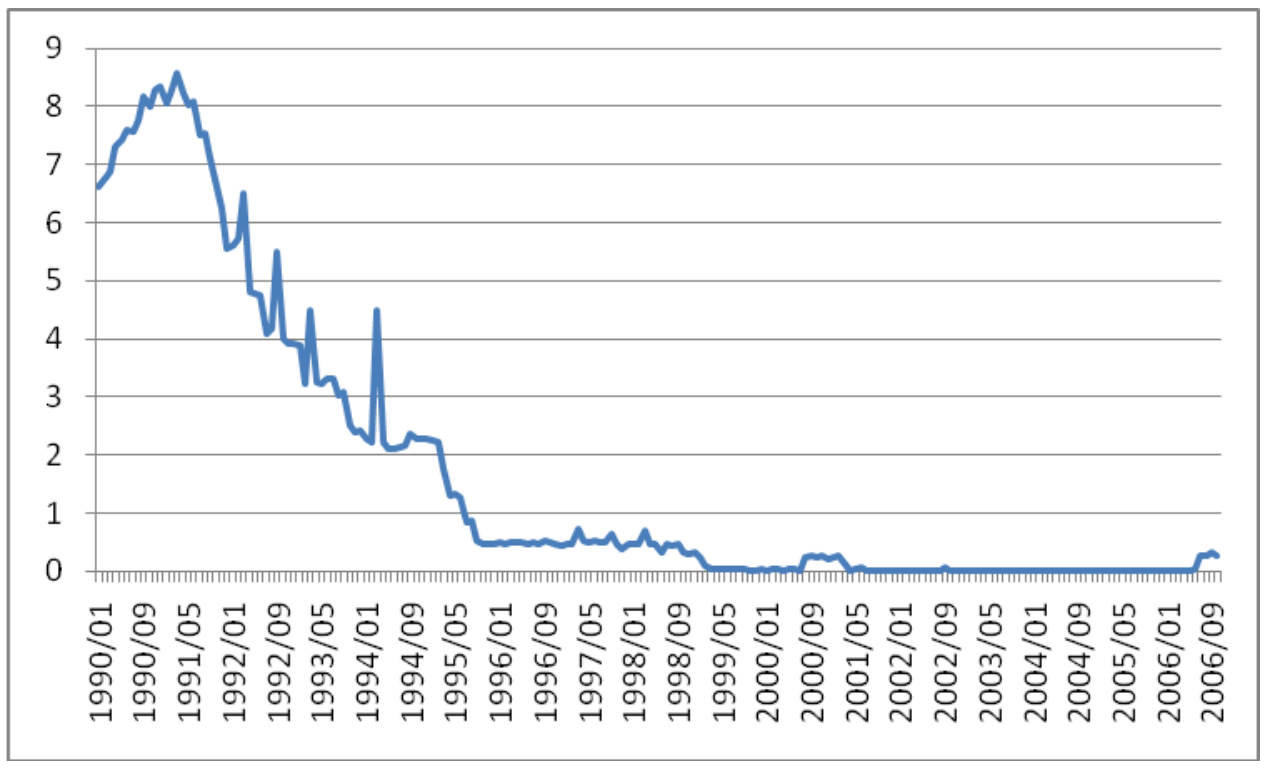

Note: Call Rate, Uncollateralized Overnight Rate, End of Month. Source: Bank of Japan. 
Figure 2: Standardized U.S. Macro Surprises

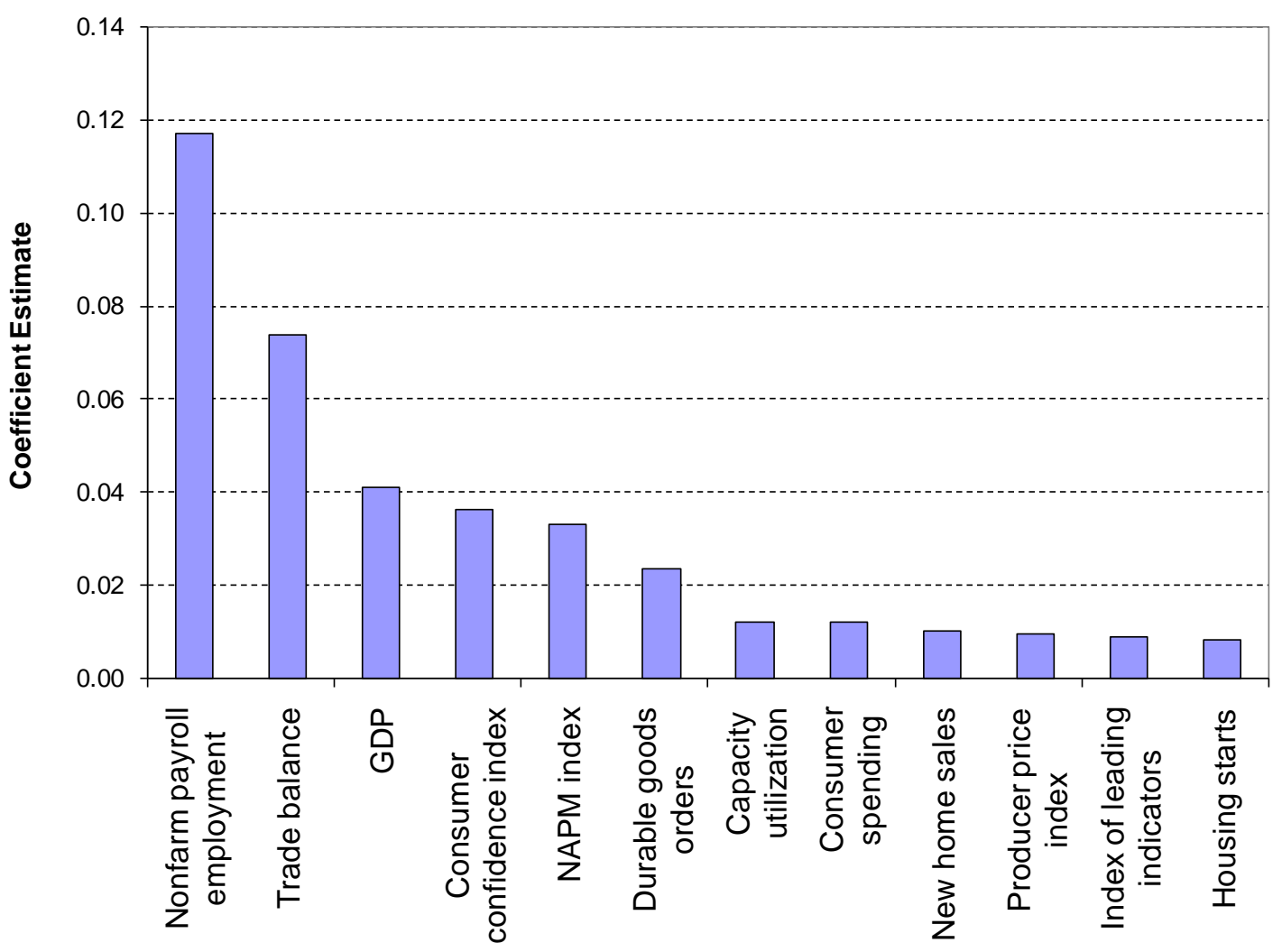

Notes:

a) The figure displays the significant coefficient estimates of the standardized U.S. macro surprises reported in the first column of Table 3. 
Figure 3: Standardized Japanese Macro Surprises

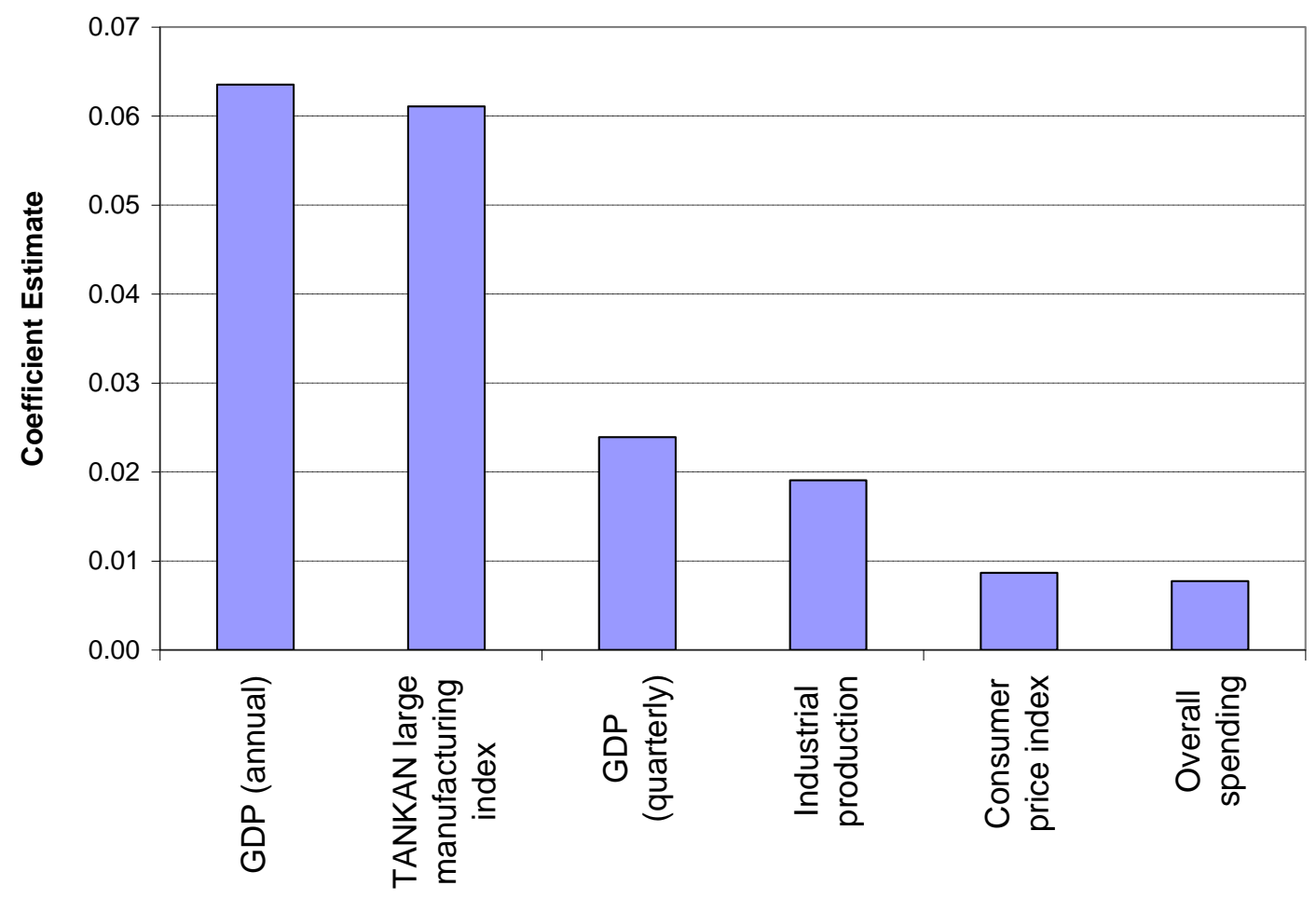

Notes:

a) The figure displays the significant coefficient estimates of the standardized Japanese macro surprises reported in the first column of Table 3.

b) To ease the comparison of the effects of U.S. and Japanese news surprises, the coefficient estimates associated with the Japanese news displayed in Figure 2 are multiplied by negative one. 
Figure 4: Average Effect of Macro Surprises by Category

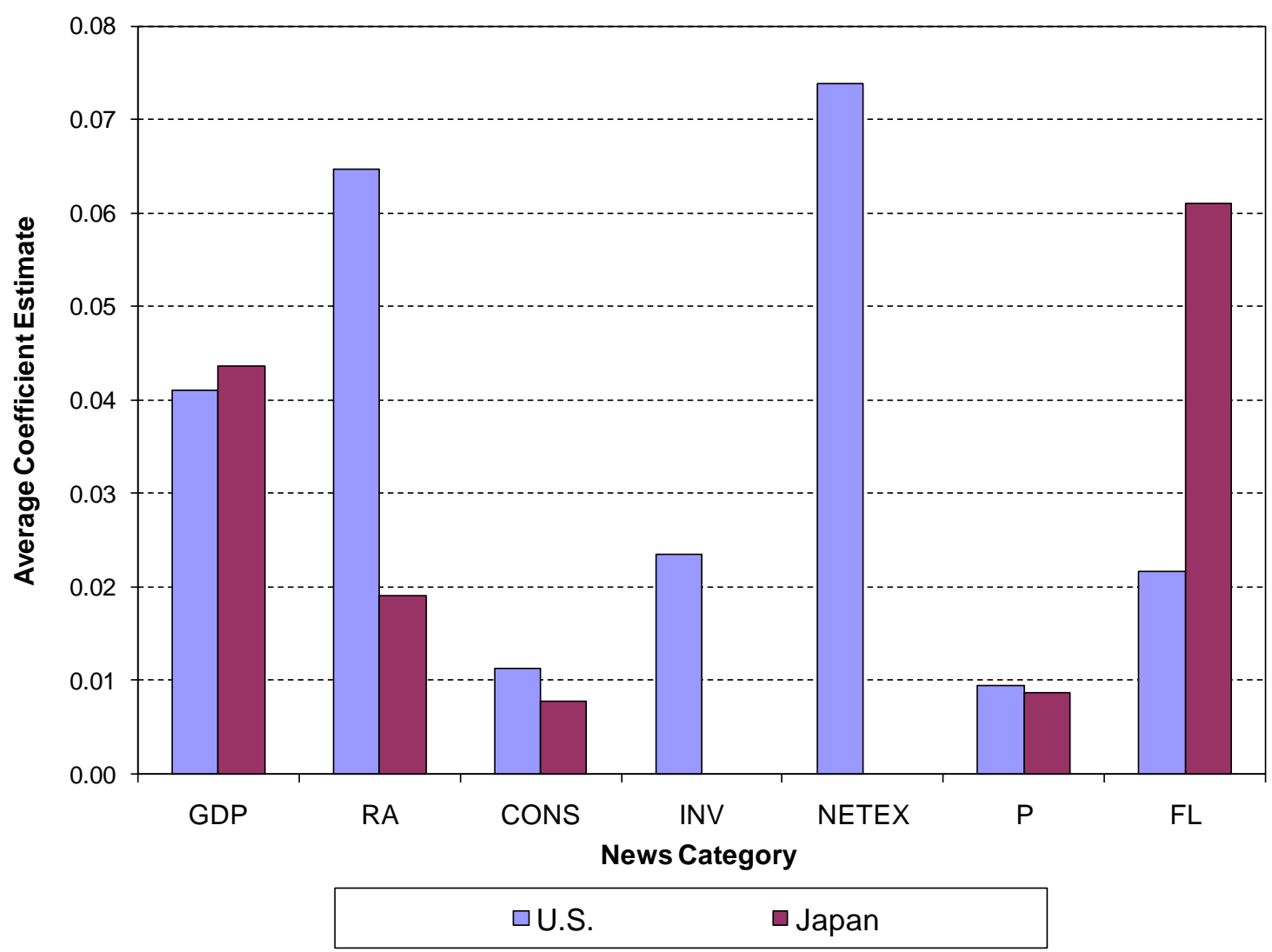

Notes:

a) The average news effect is defined as the simple average of the significant coefficient estimates within each news category.

b) Section 4 provides details on the news categories.

c) To ease the comparison of the effects of U.S. and Japanese news surprises, the coefficient estimates associated with the Japanese news displayed in Figure 3 are multiplied by negative one. 